University of Nebraska - Lincoln

DigitalCommons@University of Nebraska - Lincoln

USDA National Wildlife Research Center - Staff Publications
U.S. Department of Agriculture: Animal and Plant Health Inspection Service

August 2007

\title{
The ecology of vertebrate pests and integrated pest management (IPM)
}

Gary W. Witmer

USDA-APHIS-Wildlife Services, gary.w.witmer@usda.gov

Follow this and additional works at: https://digitalcommons.unl.edu/icwdm_usdanwrc

Part of the Environmental Sciences Commons

Witmer, Gary W., "The ecology of vertebrate pests and integrated pest management (IPM)" (2007). USDA National Wildlife Research Center - Staff Publications. 730.

https://digitalcommons.unl.edu/icwdm_usdanwrc/730

This Article is brought to you for free and open access by the U.S. Department of Agriculture: Animal and Plant Health Inspection Service at DigitalCommons@University of Nebraska - Lincoln. It has been accepted for inclusion in USDA National Wildlife Research Center - Staff Publications by an authorized administrator of DigitalCommons@University of Nebraska - Lincoln. 


\section{The ecology of vertebrate pests and integrated pest management (IPM)}

G. WITMER

\subsection{Introduction}

Across the world, vertebrates cause considerable annual damage to agriculture, property, human health and safety, and natural resources. Although some species of all vertebrate groups have been implicated in damage, the species most often involved in serious amounts of damage are birds and mammals. Agroecosystems have provided many new opportunities for vertebrates to exploit, resulting in their becoming serious "pests" with humans taking various steps to protect their agricultural resources. This conflict has intensified as the human population has increased, efforts to get more production out of traditional croplands have intensified, and marginal lands have been placed into crop production. Additionally, as the himan population has increased, people have moved into lands occupied by wildlife, resulting in more human-wildlife encounters and conflicts.

Worldwide, the kind of damage caused by wildlife is most often related to the life history strategy of the species, although the actual species and crop involved varies greatly from region to region. In most cases, the coriflict arises when wildlife are trying to acquire adequate food resources (i.e. meet nutritional needs) and forage on resources important to, and "reserved" by, humans. Examples can be identified from almost any region of the world for (1) carnivore predation on livestock, highly valued game animals, and endangered wildlife; (2). grain losses to flocking, seed-feeding avian species; (3) grassland rodents and lagomorphs consuming seeds and green foliage that would otherwise be available to livestock; (4) herding ungulates trampling and consuming crops and seedlings planted for reforestation; (5) aquaculture losses to fish-eating birds; and (6) disease transmission from wildlife to

Witmer, G. 2007. The ecology of vertebrate pests and integrated pest management (IPM). Pages 393-410 In: M. Kogan and P. Jepson, eds. Perspectives in Ecological Theory and Integrated Pest Management. Cambridge University Press, Cambridge, UK. 
humans or their livestock (Conover, 2002; Dolbeer et al., 1994). Another major problem area around the world is the consumption and contamination of stored food stuffs by rodents. In this latter case, the species most often involved are introduced, commensal rodents.

Rodent damage and its management will be emphasized in this chapter because rodents have, historically, been the major, worldwide, vertebrate pest group and there has been, and continues to be, major effort expended. to reduce their numbers and damage (Witmer et al., 1995). Rodents are implicated in all major types of damage, including significant predation on native species of animals and plants on islands to which rodents have been accidentally introduced (Witmer et al., 1998). Numerous books have appeared in the last decade from all continents or regions of the world, addressing rodent damage and its management (notably, Singleton et al., 1999). Two large tomes have been written, one from the United States and the other from Russia, dealing exclusively with the family Microtinae (voles). On the other hand, dealing with the problems caused by birds, ungulates, and carnivores pose additional "challenges" to pest management because, for example, those species are more highly visible and "important" to the general public and are usually regulated under the authority of state wildlife agencies (Conover, 2002).

While vertebrate integrated pest management (IPM) has perhaps not been as fully explored and implemented as has IPM for invertebrate, weed, and plant disease pests (e.g. Way and van Emden, 2000), there has been considerable progress in recent decades. Rodenticide application continues to be an important tool in rodent damage management by rapid and large-scale population reduction. These reductions, however, are short-term and there is a growing concern with the environmental hazards and safety issues associated with rodenticide use (Jackson, 2001). Great strides have been made to better understand the nature of rodent populations, why damage occurs, how damage can be predicted and lessened by non-lethal approaches (physical, chemical, behavioral, and cultural), and how to apply ecologically based rodent management strategies (e.g. Singleton et al., 1999). The general equipment, methods, and strategies used to management rodents, including rodenticides, have been presented in detail by Buckle and Smith (1994) and Hygnstrom et al. (1994). Many new approaches (use of disease agents and fertility control) are only in the preliminary development or testing phases for vertebrates. Many technical, regulatory, and sociopolitical hurdles need to be overcome. Additionally, much less investment is being made in solving the problems of vertebrate pests than for other agricultural pests because vertebrate 


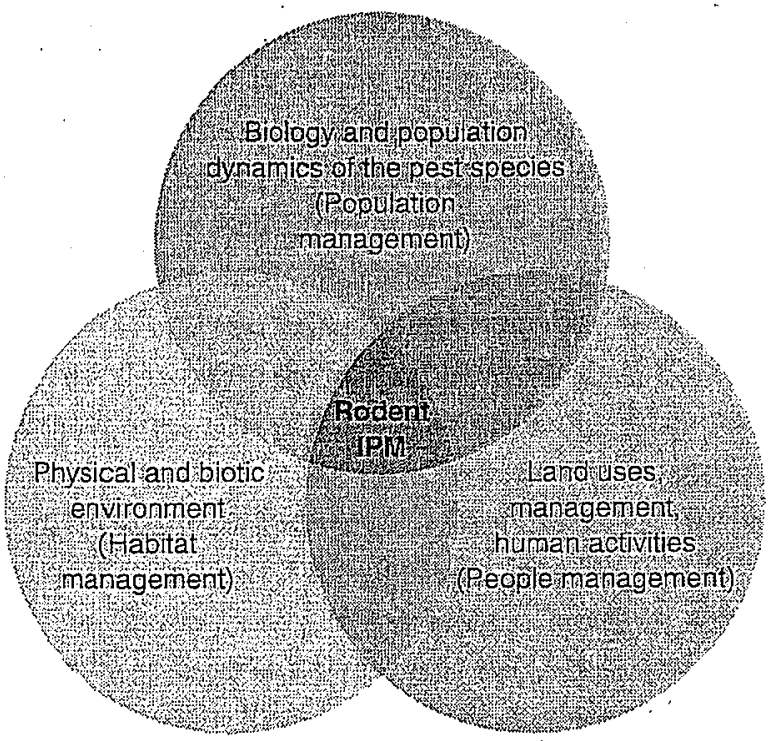

Figure 12.1. An understanding of (1) the biology and population dynamics of the pest species, (2) the ecology of the species within its physical and biotic environment, and (3) an understanding of the relationships of the pest species to the activities of humans, including land uses, management practices, and other human activities (Conover, 2002) so that we can develop effective (IPM) strategies for rodent population and damage management.

pest products are considered a "minor" part of the pest product industry (Jackson, 2001).

Solving vertebrate pest problems requires a careful consideration of (1) the biology and population dynamics of the pest species; (2) the ecology of the species within its physical and biotic environment; and (3) an understanding of the relationships of the pest species to the activities of humans, including land uses, management practices, and other human activities (Conover, 2002). It is only when we have an adequate background in those three areas that we can develop effective (IPM) strategies for rodent population and damage management (Figure 12.1). This is true because our main areas of focus are rodent population management, habitat management, and people management (e.g. Witmer et al., 2000).

\subsection{Biology and dynamics of the rodent populations}

Over a third of all manmalian species in the world are rodents. They occur on all continents with the possible exception of Antarctica; although, I venture to say, commensal rodents may have been accidentally introduced even there! Species have adapted to all lifestyles: terrestrial, 
aquatic, arboreal, and fossorial. Most rodent species are small, secretive, nocturnal, and adaptable, and have keen senses of touch, taste, and smell. For most species, the incisors grow throughout the animal's life, requiring them to be constantly gnawing to keep the incisors at an appropriate length and position. Alderton (1996) has written a fascinating account of this group of mammals and the love-hate relationship that has always existed, and presumably always will, between rodents and humans.

Rodents are lnown for their high reproductive potential; however, there is much variability between species as to the age at first reproduction, size of litters, and the number of litters per year. In the topics and subtropics, reproduction can continue throughout the year, whereas, in more northerly latitudes, reproduction is usually seasonal and limited. Under favorable conditions, populations of some species such as the Microtines can irrupt, going from fewer than 100 per ha to several thousand per ha in the period of a few months. It is in these periods that rodents will often invade crop fields and cause severe damage. It is important to note for management purposes that most rodent populations will exhibit a compensatory response to a severe population reduction with earlier age to sexual maturity, higher pregnancy rates, larger litter sizes, more litters per year, and a higher survival rate of young. Currently, there are no commercial products available to reduce the fertility of rodents although research in this area continues.

As part of this life strategy, individuals of most rodent species have short lifespans and the annual mortality rate in a population is high, often about 70\%. Although rodents, generally, have good dispersal capabilities, unless conditions are very favorable, mortality rates during dispersal are quite high. Rodents succumb to starvation, predation, disease, drowning and other accidents, and various other mortality factors. Hence, it can be seen that most rodent species exhibit a classic r-selected life strategy. An important management message is that while we can quiclily reduce a rodent population with lethal means (usually with rodenticides as discussed later), it will quickly rebound if no other actions are taken.

There are many interesting dynamics to various rodent populations that should be understood to better facilitate their management and to reduce damage (Batzli, 1992). The population goes through an annual cycle that may include high and low densities, active and inactive periods, reproductive and non-reproductive periods, and dispersal periods. To avoid inclement periods, some species exhibit a winter dormancy (hibernation), and some species have a summer dormancy (estivation) during hot, dry periods. Some species exhibit multi-year cycles; for example, the microtines often reach population peaks (irruptions) every 3-5 years. While these 
cycles have been studied for decades, the driving factor(s) has not been definitively identified, but may involve long-term weather patterns, long-term nutrient cycles, predation, and intra-specific social interactions (Krebs, 1996). For effective management of rodent populations to occur, one must take into consideration these cycles and periods of inactivity.

\subsubsection{Monitoring rodent populations}

An important principle of IPM is pest scouting. This holds true for vertebrate pests as well, although the monitoring of vertebrate populations (especially small, nocturnal, secretive species) is problematic (Engeman and Witmer, 2000a). Monitoring allows one, first of all, to determine just what species of rodents occur in the area. Several to numerous rodent species may occur in any given area, but in many situations only one species is causing the damage. Knowing what species are in the area is important in designing a control strategy, to allow for the complications of baiting and trapping that other rodents may cause, and to plan for minimizing non-target losses. Monitoring rodent populations is also very important because densities can fluctuate dramatically within a year and between years.

Obtaining accurate estimates of population density is even more difficult, as well as costly, in terms of labor, time, and resource requirements. There is considerable discussion within the wildlife profession as to the importance or need for highly accurate population density estimates. Often, an index that efficiently tracks the pest population is used. The index allows one to document changes in the population through time and space, helps define the potential magnitude and geographical extent of damage that might result from population increases, and sets the stage for the implementation of an IPM strategy. Pest population monitoring is also an important component of the assessment of the efficacy of control methods. There are a number of desirable properties to consider in the selection of a wildlife population indexing methods, including some associated with the planning stage, the in-field application of the index, and the analytical phase (Engeman and Witmer, 2000a).

A wide array of methods exist for monitoring rodent populations, including trap grids or transects, plot occupancy, open and closed hole indices for burrowing species, bait station or chew card activity and food removal, and runway or burrow opening counts (Engenian and Witmer, 2000a; Witmer and VerCauteren, 2001). Unfortunately, we rarely have a very good understanding of the relationship between the index and the actual population density or with the amount of crop/resource damage to expect. 
There are advantages and disadvantages to each index that one must carefully consider before using one. For example, the result of many indices will vary with the soil and habitat type, weather conditions, and the time of year. In some cases, it is best to use two or more indices. Additionally, some regulatory agencies may require that two indices are used, for example, when data sets for efficacy are submitted for registration purposes.

\subsubsection{Population management of rodents}

Many species of wildlife may occur in a given area and this is especially true with regard to rodents. Rodents play important ecological roles, however, and most species are not major pests. Some of the roles include soil mixing and aeration, seed and spore dispersal, influences on plant species composition and abundance, and a prey base for many predatory vertebrates. Consequently, it is important to not indiscriminately decimate rodent communities even when an effective, efficient method, such as a rodenticide bait, is available. An exception would be the control of commensal rodents in structures where the operator has much control and non-target hazards can be minimized (Corrigan, 2001). Another example is the use of rodenticides on islands where introduced rodents are causing severe damage to natural resources, there are no or few native terrestrial mammalian species present, and measures can be taken to reduce other potential hazards to very low levels (Witmer et al., 1998).

Populations of rodents can be reduced by a variety of means. While methods such as trapping, burning, flooding, and drives have been (and are still being) used in developing countries, many parts of the world have come to rely on rodenticide baits for rodent control (Singleton et al., 1999; Witmer et al., 1995). Most rodenticides were initially derived from naturally occurring plant materials; however, most are now produced synthetically. There are two general classes of oral rodenticides. Acute rodenticides (including zinc phosphide and strychnine) usually lill with a single feeding. In contrast, chronic or multiple-feeding rodenticides (including warfarin, chlorophacinone, and diphacinone) usually require a period (days) of feeding before killing. The distinction has become somewhat blurred because the second group includes first (examples given) and second (bromadiolone, brodifacoum, difethialone) generation anticoagulants. Second generation anticoagulants are very toxic and usually lxill with a single feeding. An additional group of rodent toxicants includes the fumigants (e.g. gas cartridges, aluminum phosphide, methyl bromide) which are used in building fumigation or in burrow systems that are closed after application. 
Considerable development has gone into making rodenticides effective, efficient, and relatively safe for use in buildings or the environment. This includes the development of ecologically based baiting strategies to assure safer and more effective use of rodenticides in cropland settings (Jackson, 2001; Ramsey and Wilson, 2000). In many countries, the use of rodenticides is carefully regulated by federal and/or state and provincial governments. Authorities decide who can use rodenticides and what training and record-keeping is required, along with which rodenticides and concentrations can be used and the where, when, and how of their use. Research is underway (although arguably not enough) to find new rodenticides as well as ways to make existing rodenticides more effective and less hazardous to non-target species and the environment. This is especially important in light of the fact that some rodenticides are being removed from the market and there are increasing restrictions on the use of many of these materials Jackson, 2001).

There are many aspects of the biology and ecology of a rodent species that must be understood in order to effectively use rodenticides (or even traps or bait stations). I will present only a few examples. Most rodents are neophobic, exhibiting a fear of new objects, odors, or tastes in their surroundings. As such, materials may have to be placed out for a few days to allow rodents to adjust to them. Traps may have to be placed in a locked-open position and baited for a few days before they are effective in catching rodents. Some traps are more effective in catching rodents than others and this varies widely by species. Some rodents become trap-shy after an initial capture and are difficult to recapture, while others become "trap-happy" and can be readily re-captured. These become important considerations for rodent researchers using mark-recapture techniques.

Most rodents have a good sense of taste and smell and a relatively long memory. Consequently, baits must be fresh and not moldy or rancid. Additionally, some acute rodenticides are rather unpalatable (e.g. strychnine is bitter) and others (zinc phosphide) cause sickness so quicldy that the animals may become bait-shy after an initial, non-lethal exposire. To avoid this, it is sometimes necessary to pre-bait with the grain or other base material before applying the toxic bait to help assure that the rodents will consume a lethal dose in a single feeding. This is not a problem with the anticoagulants whereby the animal slowly becomes ill over time (i.e. as internal hemorrhaging begins), but continues to feed on the toxic bait which the rodent does not associate with the gradual illness. On the other hand, some populations of rodents that have been repeatedly exposed to an anticoagulant rodenticide, such' as warfarin, have become 
resistant to the toxicant, requiring the use of a different rodenticide or a different control strategy.

The feeding habits and food preferences of rodents may shift during the course of the year, so that a bait used to deliver a toxicant or to lure rodents into traps may be much less effective during some parts of the year. For example, some rodents switch from a diet of green, succulent plant material early in the growing season to a diet primarily consisting of seeds once plants become senescent.

Another way to reduce rodent populations, theoretically, is through the introduction of disease agents or parasites. This approach has not found the success, however, that has been achieved in the control of some insect and plant populations. A major concern of using vertebrate biocides is that the agent may affect non-target species, including humans and livestock. This has been the case with the use of Salmonella spp. to control rats. Research continues, however, and a blood protozoan parasite, Irypanosoma evansi, and a liver nematode, Capillaria hepatica, are being evaluated for their ability to safely control rats and mice. Another difficulty has been the maintenance of the disease agent or parasite in the environment after the target species of vertebrate pest has been greatly reduced. There have been some successes with rabbit population control in Australia with the use of a myxoma virus and a rabbit calicivirus (Pech, 2000).

Fertility control is often considered an attractive alternative to the lethal control of rodents. There have been small-scale trials with various chemical compounds and some of these materials have shown promise. There are, however, many difficulties to overcome before any of these materials become available on the commercial market, including the need for a remote delivery system and the need to get a federal, state or provincial registration that would allow the use of compounds in the field, especially given that the effects of such compounds would probably not be species-specific (Fagerstone et al., 2002).

\subsection{Ecological relationships: physical and biotic environment}

Effective management of rodent pests also requires a thorough knowledge of the species' ecological relationships not only in natural or seminatural settings, but especially in human-altered settings. For rodents, the physical environment is comprised of various structural features (e.g. soil, water bodies, rocks, plants, buildings, roads) and weather parameters. The biotic environment consists of animals of other species which can serve as competitors (e.g. other wildlife species, livestock, or humans), especially 
for food, or as predators (e.g. carnivores, raptors, snakes, humans), and the many endo- and ectoparasites and disease organisms that can debilitate or lidl a rodent.

All rodents require food, shelter, and water. The shelter provides protection from predators and inclement weather as well as a favorable place to bear and rear their young. While rodents require water, those water requirements vary greatly by species. Some require no freestanding water at all and can meet their water needs through the metabolism of solid foods or the moisture on vegetation or other surfaces.

Some rodents can significantly alter their physical and biotic environment. Examples include beaver that flood areas by building dams across streams or by plugging culverts, creating sizable water bodies (Naiman et al., 1988). Also, pocket gophers can successfully prevent forest regeneration (after harvest, windstorm, or fire) by clipping and feeding on large numbers of tree seedlings (Engeman and Witmer, 2000b). On a smaller scale, rodents are very adept at creating burrow systems or sheltered nests (in trees, fallen logs, rock piles) to provide for their most basic cover needs. However, for the most part, rodents are at the mercy of the vagaries of their physical and biotic environment (Batzli, 1992).

Availability and palatability of foods and quantity and quality of vegetative cover vary greatly between habitats and seasons, and sometimes between years. Consequently, rodents may switch their foraging preference and strategy one or more times during the year as well as between years. The success of many management activities directed towards rodents depends upon whether or not alternative foods are available. Additionally, rodents will often retreat to certain habitats or more sheltered areas when cover or food becomes sparse (e.g. after crop harvest) or weather conditions more severe. These areas serve as refugia and can be important as source populations for future increases, dispersal, or irruptions.

Of course, the amount and quality of food and vegetative cover are greatly influenced by precipitation, temperatures, photo-period, and other climatic parameters. There has been some progress in predicting and modeling rodent population responses to long-term weather patterns (e.g. house mouse irruptions in Australia; Pech et al., 1999). As a general rule, however, theie are so many factors involved and we have such a poor understanding of those factors and rodent responses that we rarely lnow how many rodents will show up, where or when they will appear, how high their population densities will get, and if or when the population will crash. This is why so much of our rodent management strategies have been reactive rather than proactive. Only with a better understanding of these underlying 
relationships will we begin to more successfully predict rodent populations and damage and be able to design and implement effective proactive strategies (Singleton et al., 1999).

On the other hand, because of complex, and often poorly understood, ecological interactions between species, a focused attack on one rodent species will often result in the unexpected (e.g. Sullivan et al., 1998). This also applies to efforts to alter or influence predator-prey relationships.

\subsubsection{Influencing food and shelter to reduce rodent populations or damage}

Because rodent food and cover (i.e. vegetation) can be greatly influenced by human activities, there has beer considerable development of strategies to reduce populations and damage by manipulating vegetation. Many of these manipulations are not done just to reduce rodent habitat (which may be an incidental benefit) but for other reasons such as to reduce vegetative competition with crops or trees, to reduce soil pathogens, or to prepare the site for planting. Burning, plowing, disling, or herbicide application all reduce vegetative cover, at least for the short term, and hence, usually greatly reduce rodent populations. Plowing or disloing has the additional advantage of disrupting rodent burrows. All of these methods have been used extensively in reforestation, orchards, and traditional agriculture. It is interesting to note that with a trend towards no-till agriculture to reduce erosion and water loss and improve soil fertility, the benefits of reduced rodent populations are not occurring to the same extent because the soil is not disturbed to an adequate depth and plant stubble (residues) are left on the surface (Witmer and VerCauteren, 2001). Rodent problems are actually compounded when grassy refugia or fallow areas occur around the periphery of crop fields that rodents can make use of when crop fields are rather bare. Additionally, a nutritious winter food supply for rodents is created by the fall (autumn) planting of crops such as wheat, barley, and legumes. These young plants, even under snow cover, are readily available to rodents, such as voles, that are active throughout the winter.

' There has been some success in the use of lure crops or supplemental feeding to reduce damage by rodents or other vertebrates. Cracked corn or soybeans have been broadcast after drill-seeding on no-till cropland so that voles and other rodents will feed on those plants rather than feeding on newly emerged crop seedlings or digging up and feeding on planted seed (Witmer and VerCauteren, 2001). Sunflower seeds were broadcast on forest stands subject to tree squirrel damage with a subsequent reduction in tree damage (Sullivan and Klenner, 1993). A trap-barrier-system has been 
developed that uses some early planted crop fields to lure rodents in to them (Singleton et al., 1998). The lure fields are surrounded by a rodent barrier, but there are regularly spaced openings into multiple-capture rodent traps. Periodically, the rodents in the traps are collected and killed. This method has reduced rodent invasion into the surrounding crop fields that are planted at a somewhat later date.

Another approach to vegetation manipulation still under investigation is the use of endophytic grasses. These are grass varieties that contain an allaloid-producing fungus that can improve the hardiness of the grass and reduce herbivory. Some preliminary studies suggest that endophytic grass fields support lower rodent densities (Pelton et al., 1991). These grasses could potentially be used in a variety of settings, but might be very valuable around cropfields and orchards where grassy areas have served as a traditional refugia for rodents and, hence, a source of dispersing individuals.

Rodents compete for food with a variety of herbivores, including other rodent species, other wildlife, and livestock. There is some evidence that rodent populations can be reduced by intensive cattle or sheep grazing (Hunter, 1991). In some cases, the intensive grazing is done to reduce vegetative competition with tree saplings. In addition to reducing the food available to rodents, the livestock grazing may also compact the soil and disrupt burrow systems.

As a side issue, several rodent species usually occur in an area and these may be in strong competition with each other. Hence, when one species is controlled or removed; another species which only occurred in low numbers may become much more numerous and begin to cause damage. This has been noted with control or eradication of introduced rats, whereby house mice populations suddenly irrupt once their competition is gone (Corrigan, 2001).

\subsubsection{Influencing natural predation rates of rodents}

The cover needs for most rodents are quite high because of the constant threat of predation, both day and night. Because predation rates on rodents can be high, people have tried to increase predator densities as a way to reduce populations and damage. Unfortunately, prey populations usually drive predator populations, not the other way around. Artificial perches' and nest boxes have been constructed to attract hawles and owls near croplands, orchards, and grasslands. These structures, especially where natural perches were limited, were used by raptors and those raptors did prey on rodents, among other animals, in the area. There was no evidence, 
however, that the rodent population or rodent damage was substantially reduced as a result (e.g. Howard et al., 1985).

Extirpated medium- to large-sized carnivores are being re-introduced to many formerly occupied ranges in the USA. As these populations become established and expand, they may begin to help reduce the rapid increases in some vertebrate populations that have occurred in recent decades.

It should be noted, however, that the introduction of a non-native predator can have unexpected and adverse ecological impacts as has occurred on many islands with the introduction of the mongoose. It was hoped that the mongoose would help control introduced rats. Unfortunately, rats are primarily nocturnal, while the mongoose is primarily diurnal. In a number of situations, the mongoose has decimated the populations of native ground-nesting birds on islands (Witmer et al., 1996).

\subsubsection{Exclusion of rodents from areas}

I have discussed the modification of habitats to make them less supportive of rodent populations. An alternative approach to reduce or eliminate rodent damage is to exclude them from areas. This sounds attractive because it is a non-lethal approach and could, potentially, solve the problem once and for all. Exclusion devices might be physical barriers such as fencing, sheet metal, or electric wires, but could also be frightening devices, ultrasonic or vibrating devices, or chemical repellents (Buclkle and Smith, 1994; Hygnstrom et al., 1994). Unfortunately, it is very difficult to keep rodents out of an area that they want to access. They can usually get over, around, under, or through any lind of barrier put in their way. Their small size, flexibility and agility, and gnawing capability, along with their climbing and digging abilities make them a formidable adversary. They also habituate rather quickly to noxious odors, sounds, or lights. There are detailed guides available on how to rodent-proof buildings, but success is achieved only with much effort, expense, diligence, and maintenance (Corrigan, 2001; Hygnstrom et al., 1994). In open settings such as croplands or orchards, the task is much more difficult and the chance of success is much smaller. Although research in this area continues, there are few successes to report at this time.

Short, electric fences have been used with some success to exclude rodents from areas, but there are a number of concerns such as non-target hazards and excessive maintenance to keep the fences operating properly (Buclkle and Smith, 1994). Physical barriers around individual seedlings have shown some success in protecting seedlings, but, again, there are concerns about cost and maintenance as well as adverse effects on seedling 
growth (Pipas and Witmer, 1999). Predator odors have shown some effectiveness in some trials for repelling rodents and other herbivores from areas or individual plants (Mason, 1998; Sullivan et al., 1988), but little effectiveness in other trials. It has been speculated that the sulfurous odors in predator urine, feces, glandular excretions, blood/bone meal, and putrescent eggs derive from the breakdown of animal protein and serve as a cue to herbivores that a predator may actually be in the area and pose a threat to the herbivore (i.e. the potential prey; Mason, 1998). Another repellent that has shown some promise is capsaicin (the active ingredient in hot chilli peppers), but a fairly high concentration $(\sim 2 \%)$ of this expensive material is usually needed for a reasonable level of effectiveness (Mason, 1998).

\subsection{Influence of land uses, management practices, and human activities on rodent populations}

There are many things that landowners or managers can do to help reduce the risk of damage by rodents. An important first step is to familiarize themselves with the biology and ecology of the rodents (and other vertebrates that may cause damage) in the area, along with their "sign" (burrow openings, mounds, runways, nests, tracks, droppings) and how to identify damage by those species (e.g. Dolbeer et al., 1994; Hygnstrom et al., 1994). In North America; often information of this lind can be obtained at local or county extension offices or from other state, provincial, or federal agencies. University wildlife damage specialists are also important sources of information. Unfortunately, in developing countries, wildlife damage management expertise is much less readily available.

Proper sanitation around one's property can significantly reduce food and cover available to rodents (Corrigan, 2001; Singleton et al., 1999). Rubbish piles, uncovered garbage receptacles, wood and metal debris piles, rock piles, piles or bales of hay, heavy mown grass, silage and other exposed livestock feed, grain spills, and mature tree fruit on the ground are all very supportive of rodent populations. A reduction in the availability of water (e.g. standing water or wet areas) can help, but is often difficult to achieve in an outdoor setting. Within buildings, food sanitation and removal of water sources are very important in the management of commensal rodents (Corrigan, 2001).

In some cases, agricultural producers have some discretion in the crops or crop varieties that they grow, the timing of planting, and the location and size of specific crop fields (Singleton et al., 1999). Cereal grains are more likely to be damaged by rodents than some crops such as soybeans or sunflowers. 
In many cases, large monoculture crop fields will receive less rodent damage overall with most damage only occurring at the periphery of the crop fields. Valuable crops should not be grown near fallow areas, grasslands, or brushy areas that support rodents year around and serve as refugia from which rodents can rapidly disperse into crops.

In a region that is prone to periodic and substantial rodent damage, it is beneficial to have adjoining landowners cooperate in an overall strategy of reducing activities that support rodents and in rodent control activities (Jackson, 2001; Singleton et al., 1999). Otherwise, a landowner may suffer continuous rodent damage despite rodent control efforts because the surrounding landowners' properties are rodent infested with no or few control activities taking place. Landowner cooperation can also help spread the costs of rodent management activities and materials over more people, thus reducing the cost to each individual landowner. In some situations and in some places, local, state or federal government support is available where vertebrate damage to agricultural production is severe.

\subsection{Rodent IPM: bringing it all together}

As the above discussion implies, developing a rodent IPM strategy requires the careful consideration of many factors. Once the rodent species is correctly identified, it is important-to monitor its population status and associated damage, using one or more of the many methods that exist. Is the rodent abundance related to the amount of damage that occurs and can a threshold be identified for when action should be initiated? Next, one should consider the nature of the rodent species, its biology and ecology, in the setting in which the damage is occurring. How is the animal using its habitat? How is it interacting with other species? What are our actions doing to support the rodent population and to increase the amount of damage that occurs? What are our management options in terms of manipulating the rodent population, its habitat, and our activities and land use practices so that damage can be avoided or greatly reduced? What are the advantages and disadvantages of each of those management options? In general, there is a trend to start with the least invasive techniques before moving to more invasive techniques. Finally, how do we mold all those considerations into a comprehensive rodent IPM strategy that we can apply to the landscape? The strategy under consideration should be evaluated for its potential ability to achieve the objective of rodent damage reduction within the set of real world constraints, including method effectiveness and duration, the associated cost and benefits, the legality, the sociopolitical 
acceptability, and the environmental benignness of the proposed actions (Engeman and Witmer, 2000b). Of course, once we apply the strategy, we should monitor the results to see if we have achieved the desired goal of damage avoidance or reduction and, importantly, not just rodent population reduction and whether or not there were unexpected results. Because relatively little is lnown about dealing with rodent damage situations in complex landscapes (i.e. agroecosystems), we are, in essence, conducting large-scale experimental field trials. It is only with adequate monitoring and documentation that we can interpret and learn from those trials and, ultimately, improve the comprehensive rodent IPM strategy.

In some cases, decision support systems have been developed to help the landowner or manager formulate and implement a rodent damage control strategy, once the rodent population or damage threshold levels are approached or exceeded. Unfortunately, there are relatively few such systems available and most are simple dichotomous keys or simple computer programs. There is a large variability in the goals, complexity, and input and output requirements and capabilities of existing rodent decision support systems.

Important components (or modules) of a comprehensive rodent decision support system include an overview of the species biology and ecology, population and damage identification and monitoring methods, a description of damage potential and associated factors, a mechanism to evaluate alternative management techniques and the integration of techniques, a cost-benefit analysis component, computer user "friendliness" (for computer-assisted programs), and sources of additional information. An interactive training and resource package called 'Mouser' (provided as a CD-ROM; Brown et al., 2001), developed for mouse irruptions in Australia, is the most complete rodent decision support system that I have encountered, containing most, if not all, of the desirable components. There is a great need, however, to improve most existing decision support systems and to develop many more for other rodent species, crops, and situations.

It should be evident that effective rodent IPM strategies and decision support systems require substantial information that only long-term research of the given pest species and situation can provide. Furthermore, that research should be an integration of basic and applied studies. Adequate information not only can result in more effective strategies, but also better predictive power, greater support and acceptance by the parties providing the funding, and credibility of the end-users (e.g. farmers) all of which are important to assure the application and sustainability of new strategies (Singleton et al., 1999). Unfortunately, there is relatively little support for 
long-term rodent research, and, in fact, there are relatively few rodent research scientists. This situation is especially evident when one considers food losses to rodents in developing countries.

While some new tools are being developed, many traditional tools for the control of vertebrate pests and their damage are being lost as the general public and legislators take an increasingly active role in land and resource management (Conover, 2002; Jacisson, 2001). Examples include rodenticide baits, traps, and field burning. As suggested in the examples of this chapter, much more research is needed in both lethal and non-lethal means of resolving vertebrate damage situations. The research should include, but not be limited to, rodenticide, repellent, and barrier development and improvement; biological control; fertility control; and habitat manipulation. Another important research need is greater evaluation of the effectiveness of combinations of techniques, given that combinations could potentially be much more effective in the reduction of damage and may be more acceptable to the public.

An additional concern, receiving more attention in recent years, is who should pay for the cost of vertebrate pest population and damage management activities that benefit the general public or the agriculturalists of a region? Unfortunately, vertebrate damage, the cost of population and damage management, and management benefits are not evenly distributed across segments of the public and private sectors. Additional research, increased public education, and increased sensitivity by public and private sector persons involved in vertebrate pest management may help resolve some of these problems.

Rodents, the damage they cause, and the diseases they transmit have plagued human populations since the beginning of civilization. There is no reason to believe that adverse interactions will not continue for the foreseeable future as these two groups vie for resources and co-evolve in natural and human-altered landscapes, especially in agroecosystems. Therein lies the challenge for practitioners of vertebrate IPM.

\section{References}

Alderton, D. (1996). Rodents of the World. London: Blandford Books.

Batzli, G.O. (1992). Dynamics of small mammal populations: a review. In D. McCullough and R. Barrett (eds.), Wildlife 2001: Populations. New York: Elsevier Applied Science. pp. 831-50.

Brown, P.R., Singleton, G.R., Norton, G.A. and Thompson, D. (2001). Mouser (Version 1.0): a decision tool for management. Proceedings of the Australasian Vertebrate Pest Conference, 12, 199-201. 
Buckle, A.P. and Smith, R.H. (1994). Rodent Pests and Their Control. Wallingford, UK: $C A B$ International.

Conover, M. (2002). Resolving Human-Wildlife Conflicts. Boca Raton, FL: Lewis Publishers. Corrigan, R. M. (2001). Rodent Control. Cleveland, OH: GIE Media.

Dolbeer, R.A., Holler, N.R. and Hawthorne, D.W. (1994). Identification and control of wildlife damage. In T.A. Bookout (ed.), Research and Management Techniques for Wildlife and Habitats. Bethesda: The Wildlife Society. pp. 474-506.

Engeman, R.M. and Witmer, G.W. (2000a). IPM strategies: indexing difficult to monitor populations of pest species. Proceedings of the Vertebrate Pest Conference, 19, 183-9.

Engeman, R.M. and Witmer, G.W. (2000b). Integrated management tactics for predicting and alleviating pocket gopher damage to conifer reforestation plantings. Integrated Pest Management Reviews, 5, 41-55.

Fagerstone, K.A., Coffey, M.A., Curtis, P.D. et al. (2002). Wildlife Fertility Control. Technical Review 02-2. Bethesda: The Wildlife Society.

Howard, W.E., Marsh, R.E. and Corbett, C.W. (1985). Raptor perches: their influence on crop protection. Acta Zoologica Fernica, 173, 191-2.

Hunter, J.E. (1991). Grazing and pocket gopher abundance in a California annual grassland. Southwestern Naturalist, 36, 117-18.

Hygnstrom, S.E., Timm, R.M. and Larson, G.E. (1994). Prevention and Control of Willlife Damage. Lincoln, NE: University of Nebraska Cooperative Extension.

Jackson, W.B. (2001). Current rodenticide strategies. Intemational Biodeterioration and Biodegradation, 48, 127-6.

Krebs, C.J. (1996). Population cycles revisited. Journal of Mammalogy, 77, 8-24.

Mason, J.R (1998). Mammal repellents: options and considerations for development. Proceedings of the Vertebrate Pest Conference, 18, 325-9.

Naiman, R.J., Johnston, C.A. and Kelley, J.C. (1988). Alteration of North American streams by beaver. BioScience, 38, 753-62.

Pech, R. P. (2000). Biological control of vertebrate pests. Proceedings of the Vertebrate Pest Conference, 19, 206-11.

Pelton, M.R., Fribourg, H.A., Laundre, J.W. and Reynolds, T.W. (1991). Preliminary assessment of small wild mammal populations in tall fescue habitats. Tentressee Farm and Fome Science, 160, 68-71.

Pipas, M.J. and Witmer, G.W. (1999). Evaluation of physical barriers to protect ponderosa pine seedlings from pocket gophers. Western Joumal of Applied Forestry, 14, 164-8.

Ramsey, D.S.L. and Wilson, J.C. (2000). Towards ecologically based baiting strategies for rodents in agricultural systems. International Biodeterioration and Biodegradation, 45, 183-97.

Singleton, G.R., Hinds, L.A., Herwig, H. and Zhang, Z. (eds.) (1999). EcologicallyBased Management of Rodent Pests. Canberra, Australia: Australian Centre for International Agricultural Research.

Singleton, G.R., Sudarmaji and Suriapermana, S. (1998). An experimental field study to evaluate a trap-barrier system and fumigation for controlling the rice rat in rice crops in West Java. Crop Protection, 17, 55-64. 
Sullivan, T.P., Crump, D.R. and Sullivan, D.S. (1988). Use of predator odors as repellents to reduce feeding damage by herbivores $\mathrm{N}$ : northern pocket gophers. Journal of Chemical Ecology, 14, 379-89.

Sullivan, T.P. and Klenner, W. (1993). Influences of diversionary food on red squirrel populations and damage to crop trees in young lodgepole pine forest. Ecological Applications, 3, 708-18.

Sullivan, T.P., Sullivan, D.S., Hogue, E.J., Lautenschlager, R.A. and Wagner, R. G.(1998). Population dynamics of small mammals in relation to vegetation management in orchard agroecosystems: compensatory responses in abundance and biomass. Crop Protection, 17, 1-11.

Way, M.J. and van Emden, H.F. (2000). Integrated pest management in practice: pathways towards successful application. Crop Protection, 19, 81-103.

Witmer, G.W., Bucknall, J.L., Fritts, T.H. and Moreno, D.G. (1996). Predator management to protect endangered avian species. Trans. North American Wildlife and Natural Resources Conference, 61, 102-8.

Witmer, G.W., Campbell, III E.W. and Boyd, F. (1998). Rat management for endangered species protection in the U.S. Virgin Islands. Proceedings of the Vertebrate Pest. Conference, 18, 281-6.

Witmer, G.W., Fall, M.W. and Fiedler, L.A. (1995). Rodent control, research, and technology transfer. In J. Bissonette and P. Krausman (eds.), Integrating People and Wildilife for a Sustainable Future. Proceedings of the First intemational Wildifie Management Congress. Bethesda: The Wildlife Society. pp. 693-7.

Witmer, G.W. and VerCauteren, KC. (2001). Understanding vole problems in direct seeding - strategies for management. In $R$. Veseth (ed.), Proceedings of the Northwest Direct Seed Cropping Systems Conference. Northwest Direct Seed Conference, Spokane. pp. 104-10.

Witmer, G.W., VerCauteren, K.C., Manci, K.M. and Dees, D.M. (2000). Urbansuburban prairie dog management: opportunities and challenges. Proceedings of the Vertebrate Pest Conference, 19, 439-44. 